\title{
Implications for Selves and Students Through Introducing New Pedagogical Strategies Into Our Teacher Education Practice
}

\author{
Valerie A. Allison \\ Susquehanna University \\ Laura C. Haniford \\ University of New Mexico \\ Laurie A. Ramirez \\ Appalachian State University
}

\begin{abstract}
Collaborative self-study involving three mid-career teacher educators at different universities who introduced three new teaching strategies into their courses. Strategies promoted students to actively work with one another to construct and share their understandings. Researchers investigated implications for self, practices, outcomes, and relationships with students. Data included researchers' reflective journals, Zoom conferences, course materials, teaching notes, and students' survey responses and feedback. Each instructor's students were encouraged to critique and reflect on the strategies' utilization. Four themes emerged: unsettling consequences of change, renewed energy and enthusiasm for teaching, new skills and perspectives, and perceptions of student engagement, learning, and relationships.
\end{abstract}

Keywords: pedagogical innovation, teacher education, collaboration, self-study research

\section{CONTEXT}

As mid-career teacher educators, in many ways we feel we are competent instructors. We are adept at navigating our roles and responsibilities on our respective campuses, and students and colleagues respond to us in ways that suggest we have some wisdom worth sharing. Notwithstanding the validity of these claims, as veteran educators perhaps we have become a little too comfortable with established routines and practices in our classrooms. Sometimes our teaching can feel a little stale. Collectively and individually, we worry we might have become prone to coast a bit.

Finding ourselves at this professional crossroad, in this self-study we sought to intentionally reinvigorate our identities and practices as teacher educators. As we have affirmed previously (Ramirez \& Allison-Roan, 2014), we see the value in modeling for students the ideal of being students of our own practice. Loughran, Korthagen, and Russell (2008) posited, "Student teachers need opportunities to experience and learn about how experienced teachers and teacher educators take risks and develop new teaching approaches in their own practice as a fundamental form of modeling the development of pedagogical understanding" (p. 414). In this study we intentionally positioned ourselves as learners in our 
classrooms in order to critically analyze the consequences for ourselves and our students in intentionally taking risks.

This study was conducted at three institutions in different regions of the US. We are all associate professors and have been in our respective positions for more than a decade. Valerie is at a small liberal arts institution in the Northeast where she works primarily with preservice secondary students. Laura is at a large state university in the Southwest. She works with secondary education students at both the graduate and undergraduate levels. Laurie is faculty at a moderately large state university in the Southeast, and she teaches in the middle grades program serving both pre-service and practicing teachers.

The following question guided the inquiry: What are the implications for our views of self, for our teaching practices and outcomes, and for our relationships with students when we intentionally and systematically introduce new instructional strategies into our courses?

\section{THEORETICAL FRAMEWORK AND LITERATURE REVIEW}

We position this study within the traditions of self-study of teacher education practices (S-STEP) literature which advocates collaboration and reflection. Loughran and Northfield (1998) and Mena and Russell (2017) contended collaboration is foundational to self-study research, as it enhances the integrity of research and researchers. Loughran and Northfield (1998) argued working with important "other(s)" can lead to genuine transformation of practice, rather than simply rationalizing or justifying it. As we engaged in efforts to infuse new strategies into our practice, we collaborated with one another and our students, reflecting on our ideals and practices with the goal of aligning them. Collaborative reflection on practice involves others in the process of interpreting, challenging, and understanding data, creating the possibility of a multilayered impact on teaching practice (Tidwell \& Heston, 1998). Transparency of practice was an important component of this inquiry. We wanted our students to engage with us in open reflection as colearners and co-constructors of knowledge (Samaras, 2011; Walton, 2011). Pinnegar and Hamilton (2009) promoted collaboration in self-study, suggesting research is enhanced by multiple, and sometimes alternative or oppositional, perspectives as we consider our practices, potential problems, and positive aspects. Although we did not wish to experience "public failure" (p. 84), we saw value in making our work transparent to students, thereby modeling the researcher-practitioner viewpoint (Loughran, et al., 2008).

Ultimately, collaboration in self-study is seen as a means for enhancing the research's trustworthiness (Mena \& Russell, 2017). Working with others who can provide a range of perspectives also strengthens the trustworthiness of the data sources and analyses (Loughran \& Northfield, 1998; Mena \& Russell, 2017; Pinnegar \& Hamilton, 2009). We assert our research meets the standard of trustworthiness because it was conducted collaboratively with others, including students, with the shared goal of better understanding and improving our teaching practices (Taylor \& Coia, 2009).

Critical reflection, another component of self-study research, has always been central to our work as teacher educator researchers. Critical reflection, as Brookfield (2010) asserted, is not an "unequivocal concept" (p. 218). Our conceptualization of critical reflection is positioned among divergent interpretations (e.g., Brookfield, 1995; Loughran, 2002; Rodgers, 2002; Zeichner \& Liston, 1996). Reflection becomes critical when it is motivated by the desire to be just, fair, and compassionate and when it questions the criteria, power dynamics, and socio-political structures that frame our practice (Brookfield, 1995, 2010). In this inquiry we were dedicated to challenging ourselves for the purpose of moving ourselves and our students toward more egalitarian and empowering pedagogical practices. As we implemented each strategy and reflected on our efforts and their consequences, we were cognizant of the interplay between our actions and relationships of power with and among students.

Our definition of critical reflection has resulted in a stance of deconstruction where we, with students, are engaged in a "partnered practice of critical reflection," a process of collaboratively (de)constructing knowledge about teaching and encouraging one another to critically reflect (Berry \& Crowe, 2009, p. 86). Berry (2008) also invited students to critique and provide feedback on her teaching, acknowledging this is a "risky business" (p. 36) for the teacher educator, but one with potential to reframe our work. "In doing that which one advocates for ones' students, insights into teaching and learning are apprehended in practice 
that might otherwise not be fully appreciated or understood if such learning was not genuinely experienced by oneself" (Loughran \& Berry, 2005, p. 194).

This study is built on previous self-study of collaborative inquiries into teacher educators' pedagogical practices (e.g., Loughran, et al., 2008; Martin \& Dismuke, 2015; Ramirez \& Allison-Roan, 2014; Tobin \& Thomas, 2019). Tobin and Thomas's work was particularly intriguing because it resonated with our own previous scholarship (Ramirez \& Allison-Roan, 2014). In that inquiry we had engaged as learners in our courses by completing learning activities our students had described as daunting or uncomfortable, which provided us with a clearer understanding of students' lived experiences in completing challenging assignments. The current investigation gave us the opportunity to revisit those earlier insights to consider the implications for learners and ourselves when we model the process of implementing innovative practices. As Loughran, et al. (2008) posited, too frequently teacher educators advocate student teachers adopt innovative practices, "but fail to model those innovative practices" (p. 414).

Whereas, Martin and Dismuke (2015) and others (e.g., Allison-Roan \& Hayes, 2012) found benefits in their collaborations because they worked at the same institution, shared background knowledge, and were able to spontaneously "talk across the hall" (Martin \& Dismuke, 2015, p. 9); our experiences and learning benefitted from being at different institutions. We provided one another with perspectives and feedback unvarnished by individual contextual issues unrelated to the current inquiry. Because our institutions and programs vary in size, structure, and demographics, the differences enabled us to view our own instructional experiences with fresh eyes.

\section{METHODS}

This study was conducted over a fourteen-week semester in fall 2019 and included our respective courses and enrolled students (Valerie $n=12$, Laurie $n=35$, Laura $n=23$ ). We committed to implementing three instructional strategies we had not previously used: Barometer (Facing History and Ourselves, 2021), Graffiti Board (Facing History and Ourselves, 2021), and Circular Response Discussion (Brookfield \& Preskill, 2005, pp. 79-80). This study was sparked by an AERA presentation Valerie and Laura attended in which Tobin and Thomas (2019) shared insights gained through interrogating their use of the Silent Whiteboard strategy. In our case, the three strategies above were purposefully selected because each asks students to respond to open-ended prompts and actively work with one another to construct and share their understanding/views. They also positioned us as facilitators of the learning process, not as the conveyors of knowledge, and helped us model for students how they could design collaborative, student-centered instruction that allows for all student voices to be heard.

The Barometer strategy typically involves the instructor reading a series of questions or statements to the class. Students move to designated locations (e.g., along the front of the room from left to right) that represent their reaction to each prompt (e.g., from strongly agreeing to strongly disagreeing). Students might be asked to discuss with one another why they have positioned themselves in particular locations. The Graffiti Board is conducted in silence. Prompts are written on whiteboards or posters around the classroom, and students circulate to write individual responses and read and respond to one another's comments. The Circular Response Discussion (CRD) involves students in groups speaking in turn about a particular topic or reading. Each briefly summarizes what the student before them said and then adds their own perspective. No one in the group may speak out of turn and everyone must contribute once before anyone has a second opportunity to speak.

We each selected when and with which of our courses' content/concepts we utilized each strategy. We discussed how to use the strategies, when we envisioned using them, and how we hoped the strategies would support students' active participation and learning. Initially, we committed to try each strategy at least once. However, as our semesters progressed, we ended up employing some or all of the strategies more than once. Doing so was beneficial in developing our skills with the strategies and in providing further opportunity to critically reflect on the consequences for us and students in their use. Additionally, revisiting these strategies allowed us to implement some of the changes students had suggested in their feedback, allowing us to then collect additional data and compare how the changes worked for students. 
Valerie used the strategies and collected student feedback in her two senior level secondary education methods courses, "Principles of Learning and Teaching in Secondary Education" and "Differentiated Instruction and Classroom Management in Secondary Education." She also used the strategies in two other courses she taught, but she did not administer the questionnaire or de-brief with students in those courses. Laurie worked mainly with her class of seniors in a course called "Literacy, Language, and Culture in the Middle Grades," and then also used two strategies with her sophomore class, "Teaching and Learning in the Digital Age." Laura implemented them in "Issues in Secondary Education," a required class for all students seeking a secondary license. All told, Valerie collected data from seven class sessions, with Laurie and Laura collecting data from four sessions each.

With each strategy, we explained it to our students prior to implementation. Following the strategy's use, we distributed an anonymous survey soliciting students' feedback. We then discussed or debriefed the strategy, eliciting students' thoughts about what they liked, if they felt supported, what could be improved, and how they might use the strategy in their own classrooms. During class sessions we took detailed field notes regarding student responses and how we were feeling, both during implementation and in the debrief afterwards. As soon as possible after each class, we wrote reflective journals and completed an initial analysis of our individual survey data. We shared our journals on Google Drive, allowing us to read and comment on one another's writing; ask clarifying questions and identify emerging themes and patterns. We used these written reflections and the results of our individual survey results as starting points for our Zoom meetings.

As our semesters ended, we systematically immersed ourselves in our individual datasets in an iterative process, doing multiple readings to identify codes, emergent patterns, and questions for consideration as they related to our initial research question (Merriam, 1998; Samaras, 2011). In a Zoom conference, we discussed the aggregate data, exchanged ideas, and identified together the broader patterns and divergent themes (Samaras \& Freese, 2006). We prepared summaries of our individual and shared analyses, using them as interim texts (Clandinin \& Connelly, 2000) and tools for further reflection. These summaries were used to facilitate the writing process and outline our plans for extending this work beyond ourselves (Clandinin \& Connelly, 2000; Samaras, 2011). In preparing the report for this inquiry, we selected representative excerpts that illustrate the themes we had identified.

\section{RESULTS AND CONCLUSIONS}

Four overlapping themes emerged through our analysis of our individual and combined datasets: a) the unsettling consequences of change; b) renewed energy and enthusiasm for teaching; c) new skills and perspectives; and d) perceptions of student engagement, learning, and relationships.

\section{Unsettling Consequences of Change}

By our own admission, prior to initiating this study, we had become comfortable in our teaching practices, having taught our respective courses for multiple years. While we had made adjustments and adopted new texts and strategies over that time, doing so was generally on our terms and schedules. This inquiry positioned us differently, and because we were working collaboratively and had shared our selfstudy plan with students, there seemed to be more at stake. Especially early in the semester, "public failure" (Pinnegar \& Hamilton, 2009) seemed more likely than not. Rather than acting with bravado, we chose to share with our students that we were trying new strategies and inevitably we were not going to get things "perfect." Our journals documented our "reflection-on-practice" (Schön, 1983); in many cases this included how we would refine the strategy's use if we were to implement it again.

In hindsight, I should have developed questions better suited to the activity [CRD] or not given them questions at all. I also wish I had done the activity with the other reading for the day... my execution was not effective, and the activity takes a lot of time. Students' feedback "felt" more critical. (Valerie, October 3) 
I'm not sure what to think and might have to come back to this as we all discuss it together. I am definitely going to try this [Barometer] with another class, just to see if I can do it better. I'm feeling discouraged right now and not sure what to do. (Laurie, October 27)

Through journaling and conferencing about our use of the strategies - what we perceived as working well and what we might have done differently - we were able to learn from one another's successes and stumbles. Valerie was the first to implement each strategy and report to Laurie and Laura about the experiences. Below is an excerpt from her journal following the use of the Graffiti Board on the first day of the semester.

I used it as an ice breaker and to gauge how the students are feeling about the courses and related responsibilities. I asked them to respond to two prompts "What they were most excited about related to senior practicum and student teaching" and "What they were nervous about or felt the least prepared for." (Valerie, September 9)

Valerie detailed how the activity played out in the class and adjustments she could have made in her execution. Laurie used the Graffiti Board the following week, and as evidenced in her journal, Valerie's reflection informed her use of the strategy.

So, my question on the board was: In thinking about literacy in your content area specifically, what are you excited about and what are you concerned about? Like you did, Valerie, I told them they could write a response to someone else's or just put a check or something beside it. Some did checkmarks, some did exclamation points or stars, some wrote "SAME," etc. (Laurie, September 12)

Related to our imperfect practice, we each expressed feeling uneasy about the vulnerability we experienced implementing the strategies and inviting students to critique our efforts.

Sometimes I feel like I've created a monster with the level of critique my students are giving me. I'm trying to model how to be open and comfortable with it, but sometimes I'm not. (Laura, October 29)

Through responding to each other's journals and in our Zoom conferences, we provided vital support for continuing the inquiry and helped one another consider alternative perspectives of students' feedback and our own appraisals of our practice.

I am so sure this went better than you think! You picked a really hard topic to do this about (immigration). Remember, I did classroom management. I chose to make it feel a bit safer for myself--you went big. Which is awesome and should be commended. I feel like I'm getting to learn so much from your experience that I didn't open myself up to learning because I played it safe. (Laura to Laurie, December 30)

Having these opportunities to share, question, and respond to one another's experiences was not only affirming, but offered us the chance to express emotions such as fear, frustration, and disappointment. Likewise, we were able to share successes, which arguably happens too infrequently in educational settings. Ultimately, while there was an overwhelming feeling of vulnerability and discomfort, we were glad we branched out and tried something new, expanding our repertoire and learning together in a trusting, safe, and supportive space. 


\section{Renewed Energy and Enthusiasm}

Relatedly, while we each expressed feeling uncomfortable with the vulnerability the study required of us, we all also consistently noted that both the commitment to use new strategies and our collaboration with one another resulted in renewed energy and enthusiasm for our teaching.

While it [using Graffiti Board] was scary, it was also kind of exhilarating. One of the neat things about trying something new this way and being really upfront about it with my students is that I felt like we were inquiring into teaching together. I felt like it put me in a different position in relation to them. I was also learning and seeing how things went. In that way, we used my teaching as a common text to interrogate. (Laura, September 11)

I'm really glad we decided to do this project. I'm spending so much more time on my teaching than I have in recent semesters, but it feels much more satisfying. I have more energy for my classes I think because I'm doing new activities that I find interesting and I haven't seen/done a dozen times before. (Valerie, October 3)

There were a few more questions, but they emerged from the discussion, which was rich and productive (from my view). Everyone contributed to the conversation at one point. It was really engaging to me as an observer and they made some really good points... I would definitely try this activity [Barometer] again. I like it. I can see some tweaks I need to make it more effective and less problematic. (Laurie, December 6)

Through our collaboration we developed a strong therapeutic outlet, enabling us to buoy up one another in our discomfort and continue with our risk-taking and experimentation. Reading each other's journals offered us the opportunity to remain enthusiastic in trying new things in our classrooms, even when we felt things had not gone successfully. Our journals and our Zoom meetings allowed us to share our individual perspectives, which then gave us the opportunity to view our own experiences in new ways. While we felt unsettled and at times unsure, working together helped us see the value in intentionally disrupting our teaching practice. Ultimately, being so up-front with students about continuing to learn in and from our teaching resulted in more collaborative and collegial classrooms.

We each saw benefits to our professional well-being and satisfaction through having new unifying goals and purposes. Resonating with the work of Berg and Seeber (2016), we recognize that benefits from our collaboration and collegial relationship extended beyond the successful completion of this particular inquiry. As alluded to above, through coming together, we afforded ourselves the opportunity to connect with one another for authentic collegiality.

\section{New Skills and Perspectives}

We noted repeatedly in our journals and in Zoom conferences the impact the inquiry was having on our skill sets. By design, the study required us to learn three new strategies to use in our courses. We had not anticipated that the inclusion of the three strategies would result in us being more conscious of other aspects of our practice we had come to take for granted.

I rely on my own experience with activities and discussions more than I realized. I have a huge trove of information stored in my brain about how things have gone in the past, common responses, common misconceptions, common struggles, good time frames, ways to scaffold experiences, etc. Tonight, I did not have that and I felt like the ground beneath me wasn't entirely solid. (Laura, September 11)

Specifically, the three strategies relied on us to develop prompts or questions for student response. As we discovered in implementing the strategies, asking questions best suited to the strategies or our learning 
goals was challenging, as seen in Valerie's journal above. We noted missteps or missed opportunities for the strategies to be fully engaging and/or effective.

I felt rushed, probably because I had too many questions/choices and some they were totally unfamiliar with... I really wish I had been less uncomfortable with this whole thing so I could have given them a real chance to talk among themselves about their ideas/thoughts/opinions/rationales. (Laurie, October 27)

More importantly, we came to develop more critically reflective stances about our employment of questioning and discussion strategies across our teaching. This included thinking about how our selection of discussion topics and our wording of questions has implications for which students feel included, valued, and heard as well as what ideas or concepts are championed and which are discounted. The strategies employed distinct modes for students' participation. In particular, the Graffiti Board allowed students some level of anonymity, while the Barometer required students to display their perspectives very publicly. We observed our decisions about which strategy we employed with specific topics and readings bore consequences for students' learning, for their sense of safety in the classroom, and for how they engaged and ultimately contributed in the class.

We talked about the anonymity of the activity — even with the different colors. Most of them liked the anonymity. For example, on the paper asking them about their responsibilities as a teacher, the first group wrote something about teaching appropriate content. When we were debriefing the content of the lesson (as opposed to the activity itself), one of the members of that first group commented that someone had written "meh" next to that. They said they didn't understand the "meh" and they wished that person had written more about what they meant. They liked that they could challenge the sentiment without challenging the person. (Laura, September 11)

I decided to do this [Barometer] with my Literacy, Language, and Culture class on the day we were discussing immigration. This is such a divisive topic right now, politically, and I wanted to kind of gauge where students "stood" in terms of this controversial issue. I was nervous, of course, because it can be risky for students to take a stand against the "liberal" view of most students at our university. (Laurie, October 27)

Sometimes pedagogical moves and discussion topics we perceived as safe were experienced as unsafe or alienating by some students. This phenomenon was evident in Valerie's students' feedback for the Barometer. Valerie used the strategy with a reading on the topic of video gaming (i.e., Gee, 2007). She anticipated students would have a variety of experiences and opinions about gaming but the topic was not inherently unsafe for students. In facilitating the activity, Valerie felt positive about students' engagement and the usefulness of the strategy for prompting them to consider alternative perspectives. However, one student noted they did not feel engaged. Four of the 11 who completed the questionnaire indicated they could not see themselves using the strategy; two respondents provided the following explanations:

- I would be concerned about the students being afraid to say how they really feel.

- I think it could make students feel called out or left out. (Student Feedback, September 30)

Mentioned previously, this inquiry's collaborative nature brought to the foreground the value of professional collaboration. While we might have individually implemented new strategies, investigated their impact, and realized many of the insights noted above; we assert our collaboration enhanced our professional development beyond what we would have experienced working independently. Our experiences aligned with the findings of Martin and Dismuke (2015), "constant engagement and social interaction fostered accelerated individual development; we drew on the expertise and insights of both the other and the self" (p. 12). Ultimately, our shared inquiry highlighted the importance of collaborative 
opportunities for educators, at all stages of their careers, to support one another in reflecting on and refining practice (Loughran, et al., 2008).

\section{Perceptions of Student Engagement, Learning, and Relationships}

We found in students' feedback and in our observations that utilizing the strategies generally resulted in high levels of student engagement. Teacher-led large group discussion strategies often result in some students dominating while other students either remain silent or are silenced by interpersonal dynamics (Brookfield \& Preskill, 2005). Additionally, teacher-led discussions typically result in students responding more frequently to the instructor, looking for instructor approval or feedback. In our experience, it is uncommon in instructor-led discussions for students to respond to one another.

In contrast, the three strategies we employed resulted in more uniform student engagement because they required students to act (i.e., write, move, speak). Because the strategies did not position us in the center of the discussion or activity, students were prompted to look to one another to affirm or challenge their thinking and co-construct understanding.

I think it [CRD] was a worthwhile strategy, and they got more understanding from discussing in peer groups than they would have if I had led a whole-class discussion. Definitely no one was able to remain silent and the more domineering students were forced to share the floor. (Valerie, September 16)

I liked this activity [Barometer]. It got students out of their seats and moving. It got them talking to one another and discussing their reasons for placing themselves at different places in the room. It also allowed me to sort of take the temperature of the room rather quickly. (Laura, November 22)

Evidenced in compiled questionnaire data (see figures 1-3), the vast majority of students reported they found the strategies engaging and worthwhile, although there was variance among the strategies and student populations. Item 1 on the questionnaire asked students to evaluate the extent to which the "strategy was helpful in developing [their] awareness, appreciation, and/or understanding of the class session's topic." Item 2 asked students to report the extent to which they felt "supported in fully participating with the strategy." Item 3 asked for a response to "I felt engaged and interested during the activity when the strategy was used." Item 4 stated, "I would use or adapt today's strategy in my own teaching." Responses to the first three items were overwhelmingly positive. There was more variation in students' responses to item 4, with some students indicating a positive response to the strategy's use but not seeing it as appropriate in their own emerging pedagogies. Note, due to course constraints, Laurie did not administer the survey for the Graffiti Board. 
FIGURE 1

VALERIE'S STUDENT RESPONSES

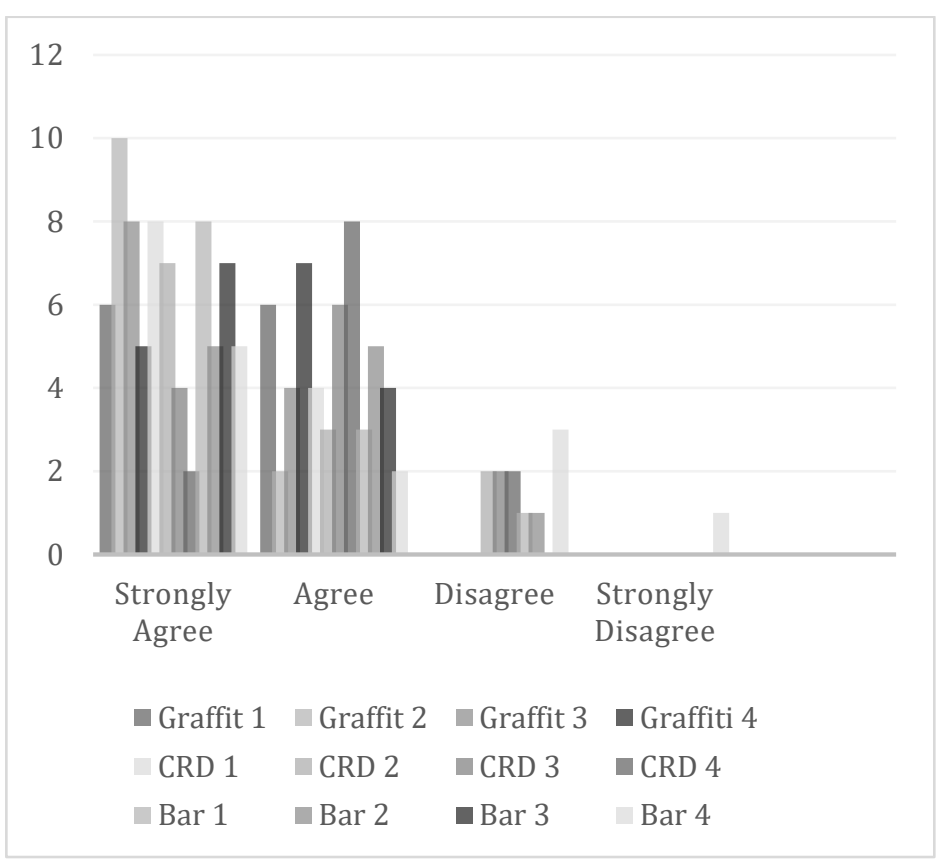

FIGURE 2

\section{LAURA'S STUDENT RESPONSES}

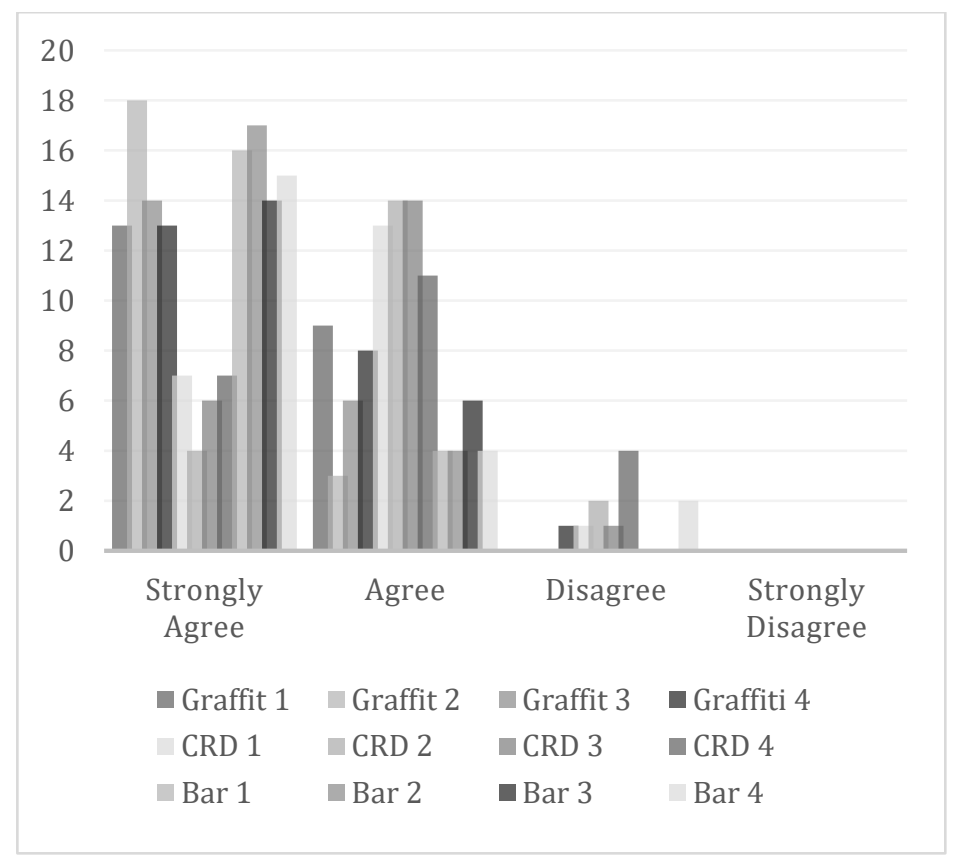


FIGURE 3

\section{LAURIE'S STUDENT RESPONSES}

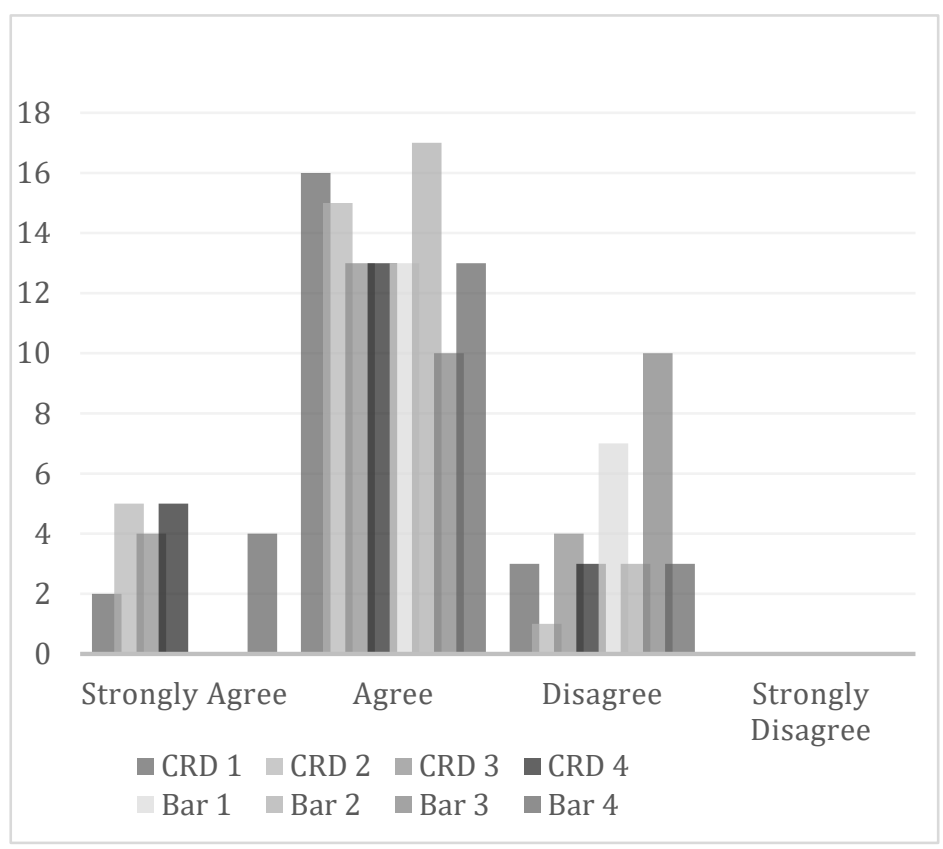

Of the three strategies, Graffiti Board was viewed most favorably across all student groups and CRD least favorably. The Barometer had the widest variation in students' responses. Since we employed the strategies with different content and goals, these findings do not point to the value of one strategy over the others. We conclude they each had merit, and we hope to continue to develop expertise in utilizing them.

The final survey item was an open-ended question: "What refinements/adjustments might the instructor make the next time she uses this strategy?" Students interpreted and answered this question in a variety of ways. Some students affirmed our efforts.

- I think it was good as is and accomplished what it needed to. (Valerie's student, September 2)

- I liked the activity because it provided everyone the opportunity to talk equally. (Laurie's student, September 23)

Other responses suggested students were theorizing about their own potential use of the strategy.

- I think this version of the activity worked well for our group, but I liked the adaptations ideas we were provided since I think I'd need to adapt the activity for, say, $7^{\text {th }}$ graders. (Valerie's student, September 30)

- I thought it was well executed. I would have liked to discuss how this could be used in STEM based courses. (Laura's student, September 11)

Finally, some students offered specific critiques and recommendations.

- I definitely think it should be done in smaller groups (3-4). In bigger groups, it was harder to stay as focused and on task. (Laurie's student, September 23)

- I felt like the questions were similar and my answer could have answered several questions. Some more modeling and scaffolding could have pulled deeper learning related to the readings/past lectures. (Laura's student, September 11)

As is evident above, not all student feedback was positive, which, as Laura noted, was sometimes difficult to hear. Laurie felt the same at times, reflecting positively on how she perceived the experience of using the CRD and then questioning her perception when reading student feedback. 
Well, there goes my whole dang theory it went better the second time around. Clearly, I felt better about it, but the students didn't seem to have much good to say. (Laurie, December 6)

Since we all work with preservice teachers on the cusp of student teaching, we felt our efforts to be transparent in our practice and our commitment to own our missteps were particularly meaningful for students. Rather than simply telling them they need to be students of their own practice when they are teachers, we each made a sustained and concerted effort to model the dispositions and skills (including collegial collaboration) associated with critical reflection on practice (see Loughran, et al., 2008)

I am finding de-briefing with my students to be a very helpful addition to my pedagogy. First, it models vulnerability and democratic principles that I hope they emulate. Second, they are being encouraged to think critically about pedagogical choices and to envision their own practice in more detail, with greater attention to their decision-making process. (Valerie, October 3)

We believe modeling critical reflection and our willingness to continue our professional growth were ultimately beneficial to our students. While beyond the scope of this study, we hope to see that our students, as they transition into their own classrooms, take to heart our efforts to reflect on our practice, to accept feedback, and to view missteps as inherent to the teaching and learning process.

Conducting this study and inviting student feedback altered the classroom dynamics. As noted above, we often felt uncomfortable or uncertain about both our pedagogy and professor/student relationships. At times, we worried we had exposed ourselves to too much scrutiny and that students were unduly harsh in their critiques. It was difficult at times to maintain an open stance and not interpret their feedback as assessments of us. By the end of the semester, most of our uneasiness had subsided. We concluded that maintaining our resolve did have a generally positive impact on our student/professor relationships and that our classrooms had developed into more democratic communities that felt safe to their members.

There were so many times this semester where I felt like I didn't know what I was doing or I felt unsure in some of the strategies we were using. But last night I had more students than I've had in a long time stay after class to thank me, to give me a hug, to tell me this was their favorite class...I think sharing my (our!) vulnerability and opening up my teaching to critique might have created a different kind of classroom environment and community. (Laura, December 4)

\section{SIGNIFICANCE}

This study was beneficial to us as mid-career teacher educators because it prompted us to move away from some of our entrenched teaching practices and be experimental again. Despite our actions being within our control, this initiative caused us to feel vulnerable, both in trying on the unfamiliar and in asking our students to evaluate our efforts. Ultimately feeling vulnerable, which is inherently part of self-study research, helped us reconnect with the emotional lives of our students, reminding us how they likely feel as they construct from scratch their pedagogies and are asked to reconcile what their emerging practices communicate about their underlying philosophies of teaching and their values concerning learners. As Berry and Russell (2016) attest,

As self-study researchers, we deliberately make ourselves vulnerable through the careful and open study of our practices...We invite others into this process with us, as critical friends, collaborators, and as an academic community, sharing ideas and perspectives and publishing our efforts. Personally and professionally, this is risky business. (p. 115) 
Through this study, we developed our adeptness with new strategies, thus expanding our repertoires. Beyond that, we benefited from having an authentic opportunity to model what it means to be a student of one's practice and the importance of collegial collaboration to ground that learning. In most cases, students observed and appreciated that we were doing what we advocated for them, and they had an unfolding example of the process (including false starts and messy, imperfect outcomes). As Loughran, et al, (2008) asserted, "Learning about teaching is enhanced when the teaching and learning approaches advocated in the program are modeled by the teacher educators in their own practice" (p. 414). As we were reminded through this study, it is important to model pedagogical approaches we are familiar with, as well as those we are still learning. Because above all, the continuous learning in and from our own practice is one of the more important lessons for our students. Perhaps because of all of the above, we found our enthusiasm for teaching rekindled and that seemed to contribute to students' enhanced engagement and stronger, positive learning communities in and beyond class meetings.

As we strive to instill in preservice teachers, learning to teach is a lifelong process. We have always recognized the importance of continually developing our practice and through this study we hoped to reconnect with the enthusiastic new teacher educators we once were. We value sharing our experiences with others, even if making ourselves vulnerable in the process. To move teacher education forward in a time where fewer and fewer are entering the teaching profession, the teacher education community must not only engage in research about our practices, but continue to learn and grow collectively. Especially over the last year of the COVID-19 pandemic, as most of us have been required to teach online; vulnerability, experimentation, and reflection has been critical. While our experiences have not always been ideal, we hope to prompt others to examine their own practices and to share their stories of success and challenge alongside their students.

\section{REFERENCES}

Allison-Roan, V., \& Hayes, M. (2012). To be heard, to be seen, to matter: Consequences of/for self in utilizing one's narrative. Studying Teacher Education, 8(2), 127-141.

Berg, M., \& Seeber, B.K. (2016). The slow professor: Challenging the culture of speed in the academy. Toronto, ON, CA: University of Toronto Press.

Berry, A. (2008). Tensions in teaching about teaching. Dordrecht, The Netherlands: Springer.

Berry, A., \& Crowe, A.R. (2009). Many miles and many emails: Using electronic technologies in selfstudy to think about, refine, and reframe practice. In D.L. Tidwell, M.L. Heston, \& L.M. Fitzgerald (Eds.), Research methods for the self-study of practice (pp. 83-98). Dordrecht, The Netherlands: Springer.

Berry, A., \& Russell, T. (2016). Self-study and vulnerability. Studying Teacher Education, 12(2), 115116.

Brookfield, S. (2010). Critical reflection as an adult learning process. In N. Lyons (Ed.), Handbook of reflection and reflective inquiry: Mapping a way of knowing for professional reflective inquiry (pp. 215-236). New York, NY: Springer.

Brookfield, S.D. (1995). Becoming a critically reflective teacher. San Francisco: Jossey-Bass.

Brookfield, S.D., \& Preskill, S. (2005). Discussion as a way of teaching: Tools and techniques for democratic classrooms (2nd ed.). San Francisco, CA: Jossey-Bass.

Clandinin, D.J., \& Connelly, F.M. (2000). Narrative inquiry: Experience and story in qualitative research. San Francisco, CA: Jossey-Bass.

Facing History and Ourselves. (2021). Retrieved from https://www.facinghistory.org/resource-library

Gee, J.P. (2007). What video games have to teach us about learning and literacy. New York, NY: Peter Lang.

Hudson-Ross, S., \& Graham, P. (2000). Going public: Making teacher educators' learning explicit as a model for preservice teachers. Teacher Education Quarterly, 27(4), 5-24.

Larrivee, B. (2000). Transforming teaching practice: Becoming a critically reflective teacher. Reflective Practice, 1(3), 293-307. 
Loughran, J.J. (2002). Effective reflective practice: In search of meaning in learning about teaching. Journal of Teacher Education, 53(1), 33-43.

Loughran, J.J., \& Berry, A. (2005). Modelling by teacher educators. Teaching and Teacher Education, 21, 193-203.

Loughran, J.J., \& Northfield, J. (1998). A framework for the development of self-study practice. In M.L. Hamilton (Ed.), Reconceptualizing teaching practice: Self-study in teacher education (pp. 7-18). London: Falmer Press.

Loughran, J.J., Korthagen, F., \& Russell, T. (2008). Teacher education making a difference: Developing foundational principles of practice. In C.J. Craig \& L.F. Deretchin (Eds.), Imagining a renaissance in teacher education (pp. 405-421). Washington DC: Rowman \& Littlefield.

Martin, S.D., \& Dismuke, S. (2015). Maneuvering together to develop new practices: Examining our collaborative processes. Studying Teacher Education, 11(1), 3-15.

Mena, J, \& Russell, T. (2017). Collaboration, multiple methods, trustworthiness: Issues arising from the 2014 International Conference on Self-study of Teacher Education Practices. Studying Teacher Education, 13(1), 105-122.

Merriam, S.B. (1998). Case study research in education: A qualitative approach. San Francisco, CA: Jossey-Bass.

Pinnegar, S., \& Hamilton, M.L. (2009). Self-study of practice as a genre of qualitative research. Dordrecht, The Netherlands: Springer.

Ramirez, L.A., \& Allison-Roan, V.A. (2014). Insights into students, practice, and self through engaging as learners in our own classrooms. Reflective Practice, 15(4), 456-467.

Rodgers, C. (2002). Defining reflection: Another look at John Dewey and reflective thinking. Teachers College Record, 104(4), 842-866.

Samaras, A.P. (2011). Self-study teacher research: Improving your practice through collaborative inquiry. Thousand Oaks, CA: Sage Publications.

Samaras, A.P., \& Freese, A.R. (2006). Self-study of teaching practices primer. New York, NY: Peter Lang Publishing, Inc.

Schuck, S., \& Segal, G. (2002). Learning about our teaching from our graduates, learning about our learning with critical friends. In J. Loughran \& T. Russell (Eds.), Improving teacher education practices through self-study (pp. 88-101). London: Routledge Falmer.

Schön, D.A. (1983). The reflective practitioner: How professionals think in action. New York, NY: Basic Books, Inc.

Taylor, M., \& Coia, L. (2009). Co/autoethnography: Investigating teachers in relation. In C.A. Lassonde, S. Galman, \& C. Kosnik (Eds.), Self-study research methodologies for teacher educators. (pp. 169-186). Rotterdam, The Netherlands: Sense Publishers.

Tobin, J., \& Thomas, A.M. (2019, April). The pedagogical voice of the Silent Whiteboard: Pedagogical embodiments in a teacher educator collaborative self-study. Presentation at the Annual Conference of AERA in Toronto, ON, CA.

Walton, J. (2011). A living theory approach to higher education. Educational Action Research, 19(4), $567-578$

Zeichner, K.M., \& Liston, D.P. (1996). Reflective teaching: An introduction. Mahwah, NJ: Lawrence Erlbaum Associates. 